\title{
The General Health of the Intensive Care Unit Nurses of the Selected Teaching Hospitals Affiliated to Iran University of Medical Sciences (2019)
}

\author{
Fatemeh Alipoor ${ }^{1}$, Mehrnoosh Inanloo ${ }^{2}$
}

\begin{abstract}
Background \& Aims: Job plays a key role in health. The issue of health in hospitals is of a greater essence since the health of nurses is at a higher risk due to constant contact with patients. Important factors threatening the health of nurses include the stressful nature of the profession, high workload, ambiguity in job roles, communication problems and interpersonal conflicts, emotional problems, facing unpredictable situations, work shifts variables. Prolonged contact with critically ill patients and providing intensive care to specific patients predisposes nurses to a variety of mental disorders. Nurses working in intensive care units are at higher risk than nurses working in outpatient clinics. Reducing the feeling of well-being and health, despite the effect on nurses health, can indirectly effect the health of the community by reducing the quality of services provided by them. Because the environment of intensive care units is full of stressful conditions, including the observation of deaths, diseases and also the pressures exerted by patients companions on nurses, therefore, identifying the variables that are related to improving the general health of nurses working in intensive care units is more important than other occupations. The present study aimed to assess the general health of the intensive care unit (ICU) nurses of the selected teaching hospitals affiliated to Iran University of Medical Sciences.

Materials \& Methods: This descriptive-correlational study was conducted on 193 ICU nurses of the selected hospitals affiliated to Iran University of Medical Sciences during January-May 2019. The participants were selected via stratified random sampling based on the inclusion criteria. Data were collected using a demographic questionnaire and the general health questionnaire (GHQ-28). The GHQ-28 consists of 28 items and four dimensions of physical examination, anxiety and insomnia, social functions, and depression. The items in the GHQ-28 are scored based on a Likert scale (Not at All, Normal, Abnormal, and Extremely Abnormal) within the score range of $0-3$. The scores of the dimensions were summed up, and the total score was calculated within the range of $0-84$. The general health score is 23 and six in all the dimensions, so that the scores of $\leq 23$ in general health and scores of $\leq 6$ in the other dimensions represent healthy individuals or the absence of disease syndromes. In addition, the scores of $\geq 24$ in general health and the scores of $\geq 7$ in the other dimensions are indicative of disease syndromes. Data analysis was performed using descriptive statistics (mean, standard deviation, frequency, and percentage) and inferential statistics, including the analysis of variance, independent t-test for the normal variables, Kruskal- Wallis test for the non-normal variables, and simultaneous multiple linear regression analysis. Results: The mean score of general health status was $28.86 \pm 6.53$, which indicated the average health status of the nurses with disease symptoms. Moreover the dimensions of physical symptoms $(7.60 \pm 2.29)$ and social functions $(11.57 \pm 1.81)$ showed health disorders, while the dimensions of anxiety and insomnia $(6.74 \pm 3.31)$ and depression $(2.95 \pm 3.00)$ were indicative of no health symptoms. Furthermore, significant correlations were observed between general health and the variables of age $(\mathrm{P}=0.023)$, marital status $(\mathrm{P}<0.001)$, economic status $(\mathrm{P}=0.023)$, and work shift $(\mathrm{P}=0.01)$. In addition, the results of the multiple linear regression analysis indicated that economic status $(\mathrm{P}=0.004)$ and marital status $(\mathrm{P}=0.010)$ became significant in the model, and their regression coefficients were estimated at 0.38 and -0.10 , respectively, which showed the effects of these variables on the general health of individuals. In other words, the mean score of general health of the nurses with the income of
\end{abstract}

\footnotetext{
1. Critical Care Nursing, School of Nursing and Midwifery, Iran University of Medical Sciences, Tehran, Iran ${ }^{2}$. Nursing Care Research Center, School of Nursing and Midwifery, Iran University of Medical Sciences, Tehran, Iran (Corresponding author) Tel: +98-21-88882885 Email: inanlou.m@iums.ac.ir
} 
less than 1.5 million was higher by 0.38 (lower general health) compared to those with the income of more than four million. Moreover, the general health score of the single nurses was lower by 0.10 (better general health) compared to the married nurses.

Conclusion: Given the vital role of nurses as a treatment staff, it is necessary to pay attention to the problems of this group and try to maintain their health. Nurses who are not in good general health are unable to perform proper care such as physical and mental support for patients and this increases the risk of mistakes and occupational accidents, the consequences of which ultimately affect the patient and the nurse. Finally, it seems that the attention of officials to factors related to nurses health can be an important step in maintaining their health and inceasing their efficiency and will increase the quality of work. According to the results, special attention must be paid to the health of ICU nurses. Our findings in this regard could lay the groundwork for further research to adopt appropriate strategies for the improvement of the work conditions and skills training in an attempt to promote the general health of employees.

Keywords: General Health, Intensive Care Units, Critical Care Nurse

\section{Conflict of Interest: No}

How to Cite: Alipoor F, Inanloo M. The General Health of the Intensive Care Unit Nurses of the Selected Teaching Hospitals Affiliated to Iran University of Medical Sciences (2019). Iran Journal of Nursing. 2020; 33(125):1-12.

Received: 2 May 2020

Accepted: 1 Aug 2020 


\title{
سلامت عمومى يرستاران بخشهاى مراقبت ويزه مراكز آموزشى درمانى منتخب دانشكاه علوم يزشكى ايران در سال هوبه
}

\author{
فاطمه عليبور '، مهرنوش اينانلو'
}

جكS:

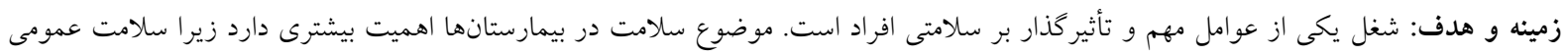
يرستاران به دليل ارتباط زياد با بيماران، در معرض خطر بيشترى قرار دارد. هدف مطالعه حاضر بررسى سلامت عمومى يرستاران بخشهاى مر اقبت ويزه

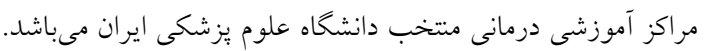

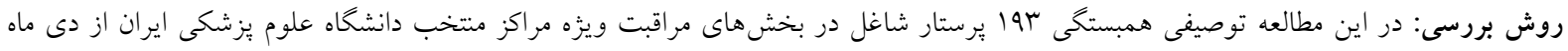

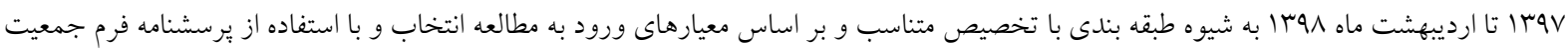

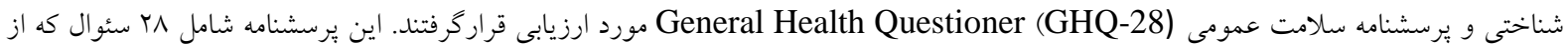

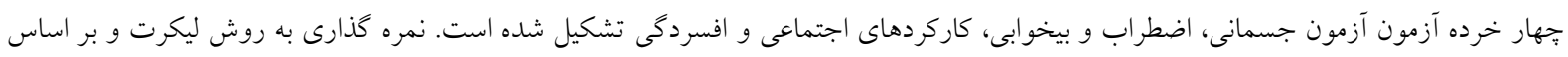

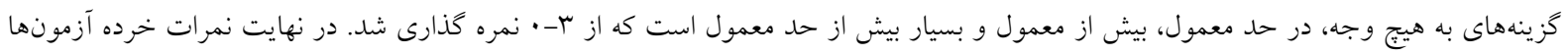

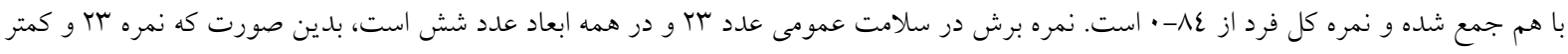

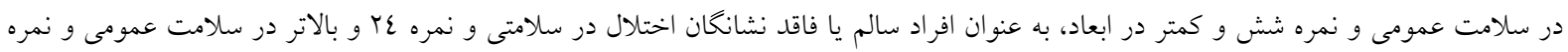

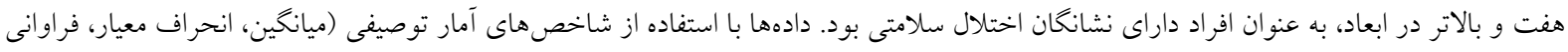

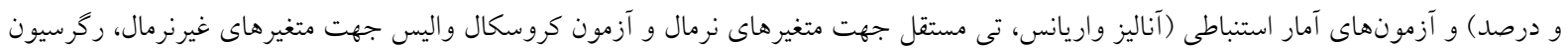

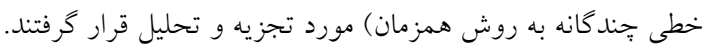

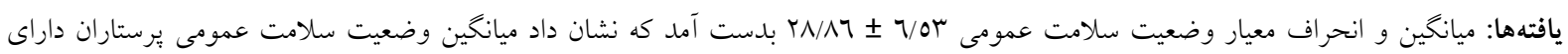

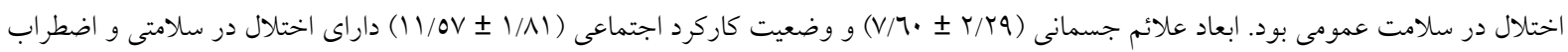

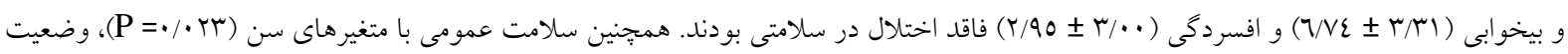

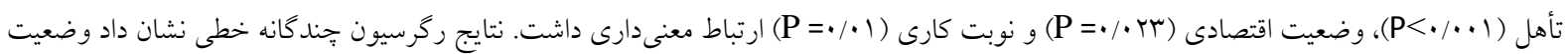

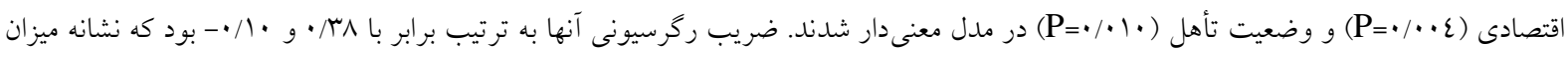

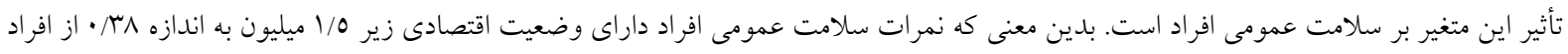

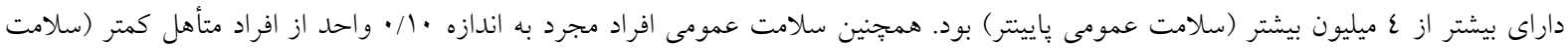
عمومى بهتر) بود. نتيجه گيرى كلى: نتايج مطالعه حاضر نشان مىدهد كه توجه به سلامت يرستاران شاغل در بخشهاى مراقبت ويزه ضرورى مىباشد. نتايج يزوهش

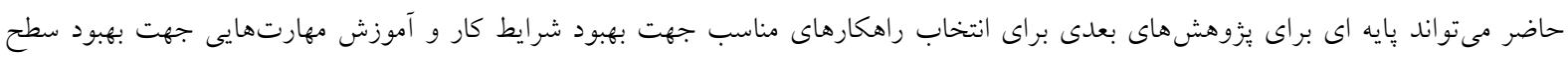
سلامت عمومى كاركنان باشد. كليد وازهها: سلامت عمومى، بخشهاى مراقبت ويزه، برستار مر اقبت ويزٔه

$$
\text { تاريخ دريافت: تاريخ بنافع: ندارد }
$$

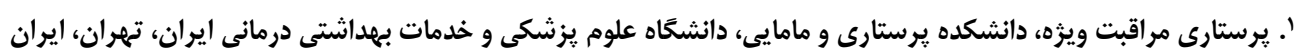

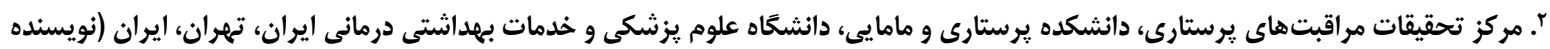


مىتواند منجر به بروز اختلالات روانشناختى شود (^).

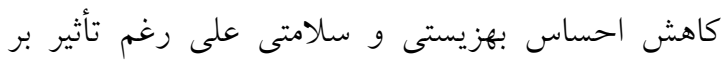

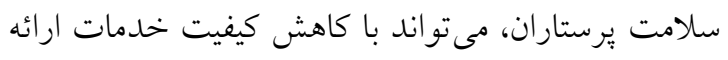

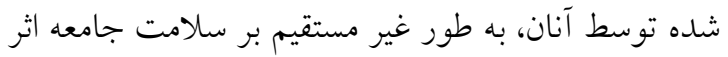

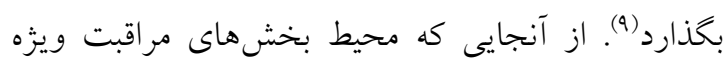
مملو از شرايط استرس زا، از جمله مشاهده مرى و و ميرها، بيمارىها و نيز فشارهاى وارد شده از سوى همراهان

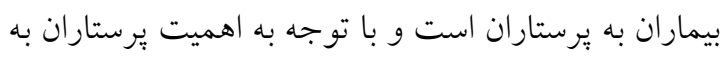

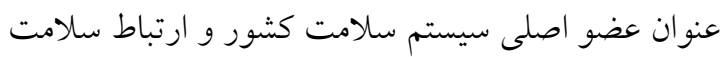

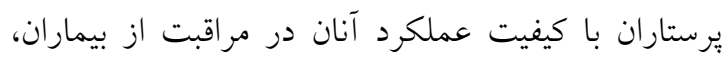
بنابراين مطالعه حاضر با هدف تعيين سلامت عمومى يرستاران شاغل در بخشهاى مراقب ويزه بيمارستانهاى منتخب علوم بزشكى ايران انجام شده است.

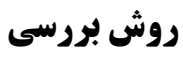

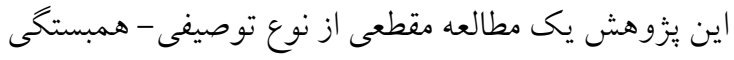

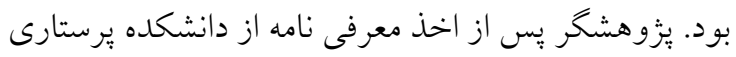

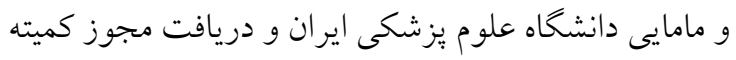
اخلاق با كد IR.IUMS.REC.1397.345 و و ارائه آن

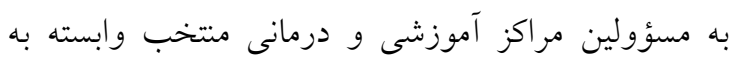
دانشخاه علوم يزشكى ايران اقدام به جمع آورى داده نمود.

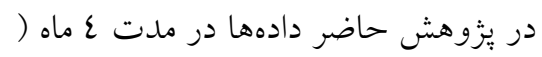

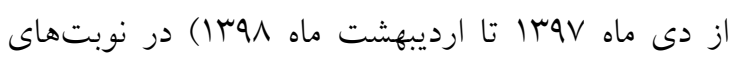

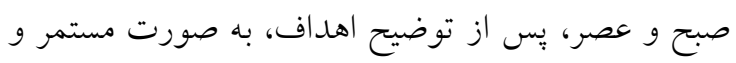

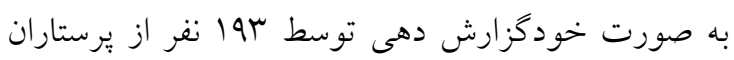
بخشهاى مراقبت ويزه با توجه به رضايت نامه كتبى و و

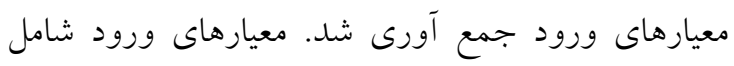
حداقل مدرى كارشناسى و حداقل دو سال سابقه كار در ورد

$$
\text { بخش هاى مراقبت ويزه بود. }
$$

در اين مطالعه از روش نمونه گيرى طبقهاى با تخصيص بودي متناسب استفاده شد و حجم نمونه بر اساس سطح اطمينان

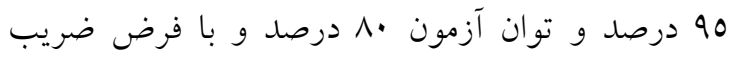

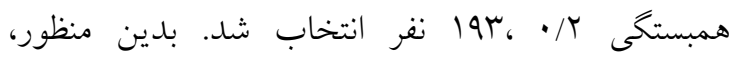

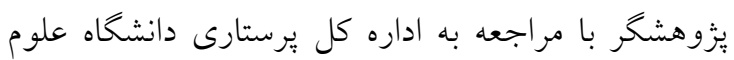

\section{مقدمه}

از ميان بديدهها و عو امل مختلف تأثير كذار بر بازده شغلى مأل و سطح كارايى فرد، سلامت جسمى و روانى است (1).

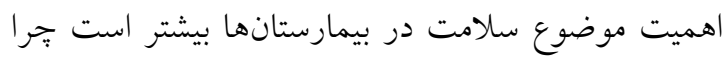
كه در بيمارستانها، سلامت برستاران به دليل ارتباط زياد

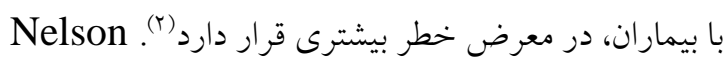

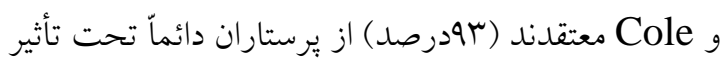
عوامل استرس زاى محيط كار قرار مى گيرند كه مىتواند

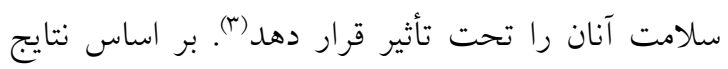

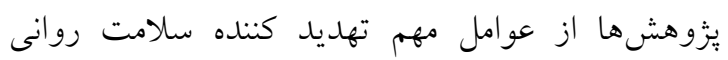
برستاران مى توان به ماهيت استرس زاى اين حرفه، فشار

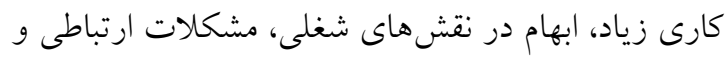

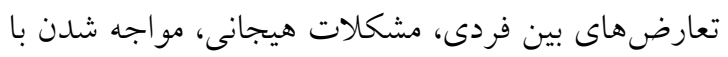
موقعيتهاى غير قابل بيش بينى، نوبتهاى كارى متغير،

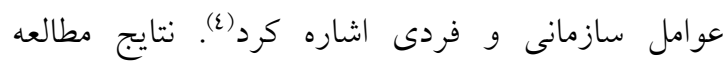
Noroozi ( سٓ//) از يرستاران سطح سلامت عمومى مطلوبى نداشته و حداقل يكى از و اكنشهاى هيجانى استرس، اضطر اب و و

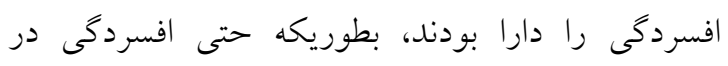
يرستاران شاغل در بخش مراقبت ويزه نسبت به يرستاران

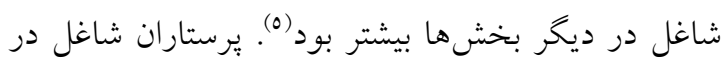

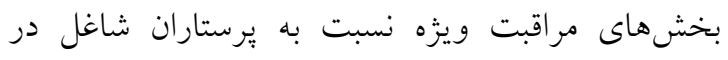
كلينيكهاى سريايى در معرض خطر بيشترى قرار دارند (7).

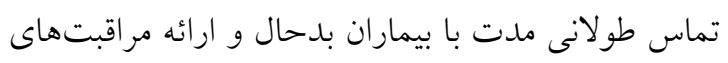

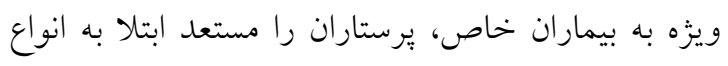

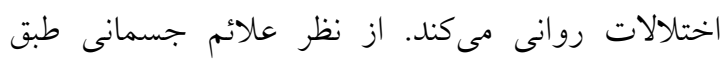
مطالعات VV/T درصد يرستاران از بى خوابى و 77/0

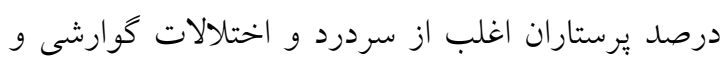
rآ7 درصد اغلب از تاكيكاردى و درد مفاصل شكايت دارند (v). از طرفى بحران ايجاد شده در ارتباط با بيمارى

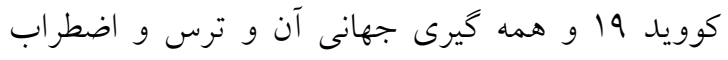
ناشى از ابتلاى احتمالى، بار روانى زيادى را بر كادر درمان

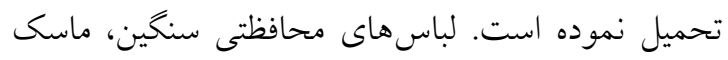

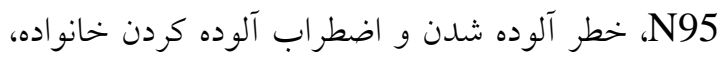


روش دوبــاره ســنجى، دو نيمه كردن و آلفــاى

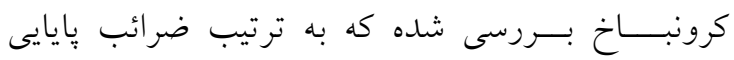

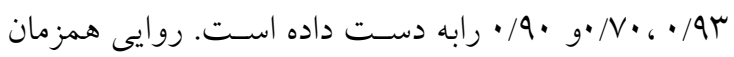

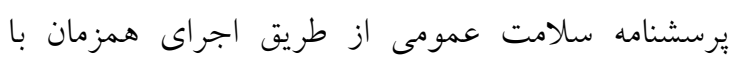

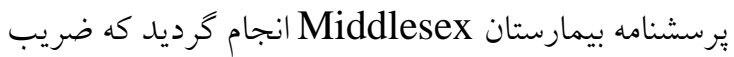

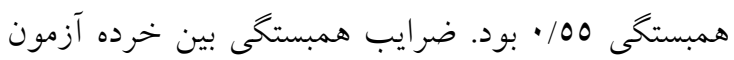
هاى اين يرسشنامه با نمره كل در حد رضايت بخش و بين (Ir)

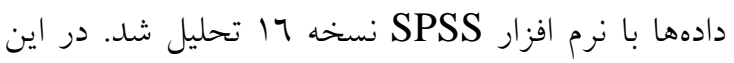
مطالعه از آمار توصيفى (فراوانى، درصد فراوانى، ميانخين و

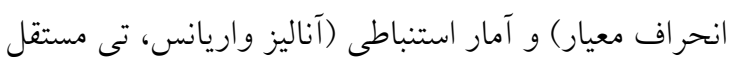

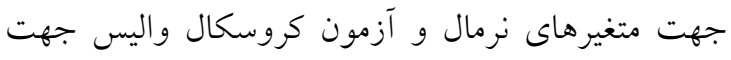

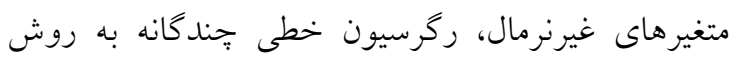

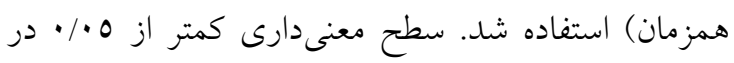

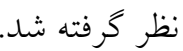

\section{يافتهها}

در اين مطالعه سوا يُرستار مراقبت ويزه مورد مطالعه قرار كر فتند. تمامى شركت كنند كان در مطالعه زن و بيشتر آنان

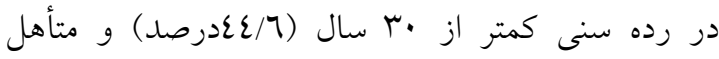

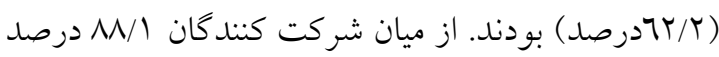

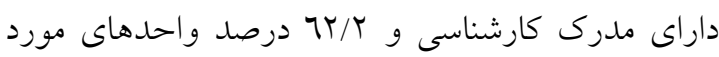
يُزوهش به صورت استخدام رسمى در بخش هاى مر مراقبت ويزه مشغول به كار بودند. سابقه كار اقليت يرستاران

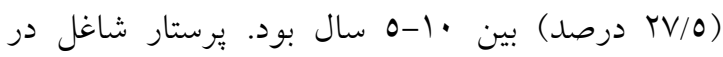

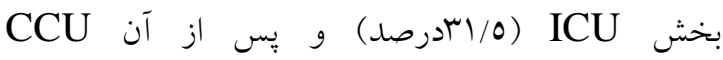

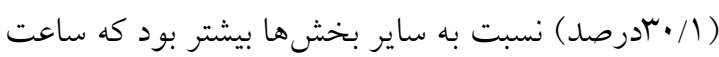
اضافه كار /0/1ع درصد از يرستاران بيشتر از •7 ساعت در ماه و در آمد ماهيانه بيشتر يرستاران يعنى ه/ هو درصد از آنان بين ع- 1/0 ميليون تومان در ماه بود. (جدول شماره
يزشكى ايران، تعداد بخشهاى مراقبت ويزه و تعداد

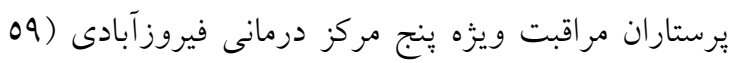

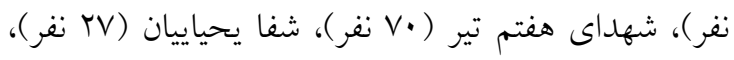

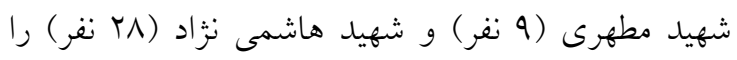
مشخص كرد. جمع آورى دادها با استفاده از فرم جمعيت شناختى ( سن، جنسيت، ميزان تحصيلات، وضعيت تأهل، وضعيت اقتصادى، نوبت كارى، وضعيت استخدام، سابقه كار، اضافه كار و نام بخش) و برسشنامه General (GHQ-28) Health Questionaire

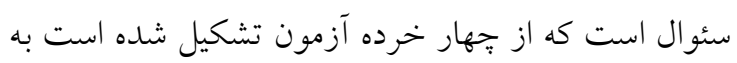

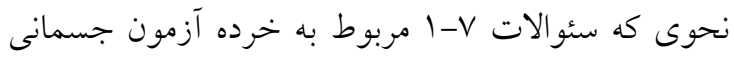

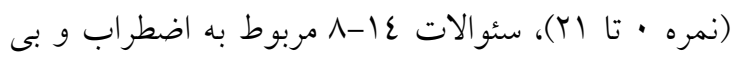

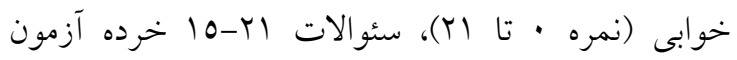

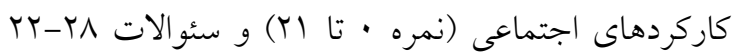

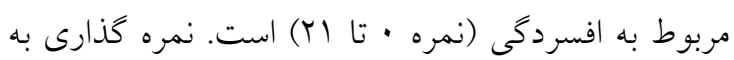

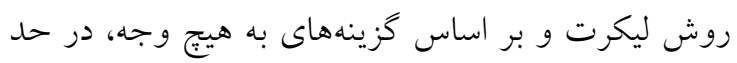

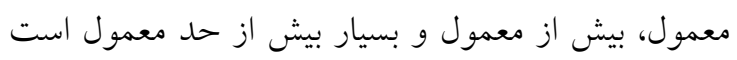

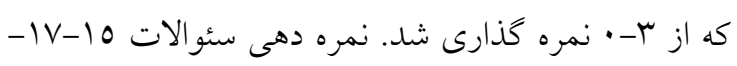

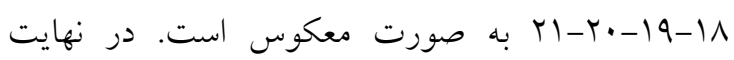

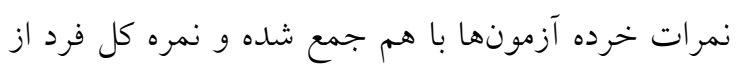

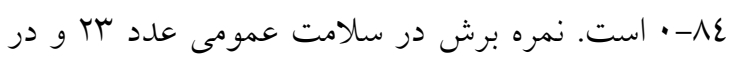
همه ابعاد عدد شش است، بدين صورت كه نمره بr بات و

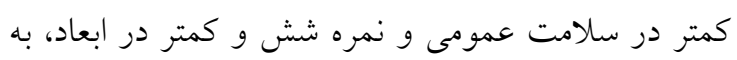
عنوان افراد سالم يا فاقد نشانحان اختلال در سلامتى و نمره

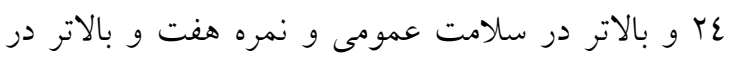
ابعاد، به عنوان افراد داراى نشانگان اختلال سلامتى بود (•).

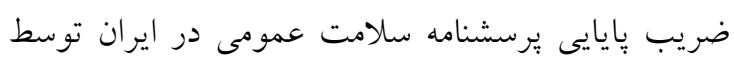
Ebrahimi و همكاران M 1 درصد عنوان شده است (11). Taghavi

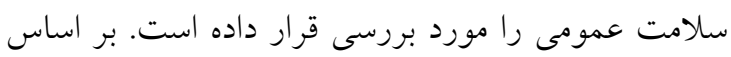

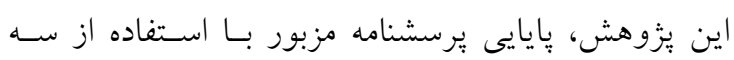


جدول شماره ا: توزيع فراوانى جمعيت شناختى يرستاران بخش مراقبت ويزه

\begin{tabular}{|c|c|c|}
\hline فراوانى (درصد) & \multicolumn{2}{|c|}{ مشخصات جمعيت شناختى } \\
\hline$\wedge\rceil(\varepsilon \varepsilon / 7)$ & كمتر از •• & \\
\hline$\wedge)(\Sigma r)$ & $r q-r$. & سن، سال \\
\hline$r \mu(11 / \Lambda)$ & $\varepsilon q-\varepsilon$. & \\
\hline$r(1 / 7)$ & م 0 و بيشتر & \\
\hline \multicolumn{3}{|c|}{ Mean \pm SD } \\
\hline • & مرد & 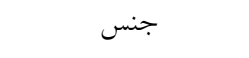 \\
\hline $194(1 \cdots)$ & زن ان & \\
\hline$V \Psi(Y V / \Lambda)$ & مجرد & وضعيت تأهل \\
\hline $1 Y \cdot(T r / T)$ & 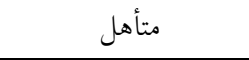 & \\
\hline$I V \cdot(\Lambda \Lambda / I)$ & 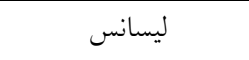 & تحصيلات \\
\hline$r(11 / 9)$ & فوق ليسانس و بالاتر & \\
\hline $7(r / 1)$ & كمتر از 1/0 & \multirow{3}{*}{ درآمد (ميليون تومان) } \\
\hline$|\wedge|(94 / \Lambda)$ & $1 / 0-\varepsilon$ & \\
\hline $7(r / 1)$ & بيش از ع & \\
\hline $1 \varepsilon(V / \Gamma)$ & صبح & \multirow{3}{*}{ 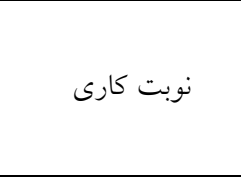 } \\
\hline 队 $(19 / 7)$ & 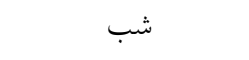 & \\
\hline$|\varepsilon|(V / /)$ & در كردش & \\
\hline $1 T \cdot(T T / T)$ & رسمى & \multirow{3}{*}{ وضعيت استخدام } \\
\hline$\varepsilon \cdot(Y \cdot / V)$ & 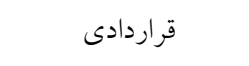 & \\
\hline r (IV/I) & طرحى & \\
\hline$V \cdot(r \top / \mu)$ & $1-0$ & \multirow{4}{*}{ سابقه كار، سال } \\
\hline Or $(Y V / \varepsilon)$ & $0-1$. & \\
\hline$V \cdot(r / / \Gamma)$ & بيشتر از · & \\
\hline & Mean \pm SD & \\
\hline $71(\Gamma / / 0)$ & ICU & \multirow{4}{*}{ 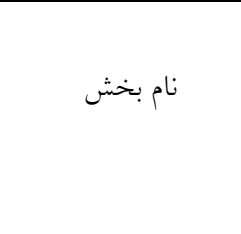 } \\
\hline O^ $(\mu \cdot / 1)$ & $\mathrm{CCU}$ & \\
\hline$O V(Y q / 0)$ & 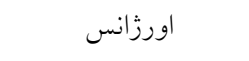 & \\
\hline $\operatorname{IV}(\Lambda / \Lambda)$ & دياليز & \\
\hline ro $(\mid N / 1)$ & $\cdot-\varepsilon \cdot$ & \multirow{4}{*}{ اضافه كار (ساعت) } \\
\hline$V \backslash(r / \Lambda)$ & $\varepsilon \cdot-\urcorner \cdot$ & \\
\hline$\Lambda V(\varepsilon 0 / 1)$ & بيشتر از • & \\
\hline- & Mean \pm SD & \\
\hline
\end{tabular}

نشانگان اختلال در سلامتى بود. ميانخين و انحر اف معيار

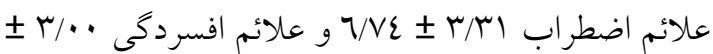

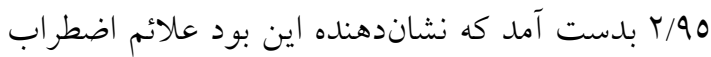

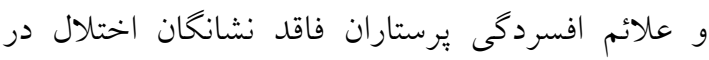
سلامتى بود. (جدول شماره Y).
ميانخين و انحراف معيار وضعيت سلامت عمومى T/Or T/N/AT \pm

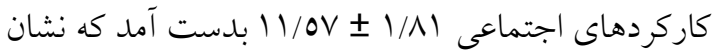
دهنده اين بود ميانخين وضعيت سلامت عمومى، علائم

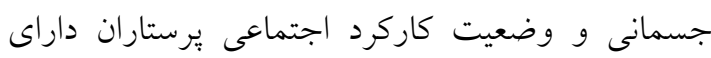


جدول شماره r: شاخص عددى و توزيع فراوانى وضعيت سلامت عمومى، علائم جسمانى، علائم اضطراب، وضعيت كاركرد اجتماعى و

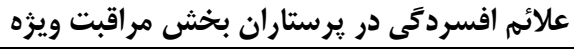

\begin{tabular}{|c|c|c|c|c|}
\hline وضعيت سلامت نشانگان اختلال & فاقد نشانگان اختلال در & بيشينه- كمينه & 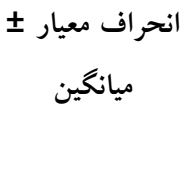 & سلامت عمومى و ابعاد آن \\
\hline $17 \varepsilon(10)$ & ra (10) & $17-\varepsilon 9$ & rN/AT \pm T/Or & وضعيت سلامت عمومى (عـ-^•) \\
\hline $\mid r \wedge(7 T / \Gamma)$ & $70(M / \mathrm{V})$ & $r-1 r$ & $V / \neg \cdot \pm r / r q$ & وضعيت جسمانى (II-·•) \\
\hline $90(\varepsilon 9 / 4)$ & $9 \wedge(0 \cdot / 1)$ & $\cdot-11$ & $T / V \varepsilon \pm r / r 1$ & وضعيت اضطراب و بىخوابى (الY-•) \\
\hline $1199(9 V / V)$ & $\varepsilon(Y / l)$ & $7-1 V$ & $11 / 0 V \pm 1 / 11$ & وضعيت كاركردهاى اجتماعى ( آY-•) \\
\hline$r \wedge(1 \varepsilon / 0)$ & $170(10 / 0)$ & $\cdot-10$ & $r / 90 \pm r / .$. & وضعيت افسردگى (اIY-•) \\
\hline
\end{tabular}

جدول شماره س: شاخص هاى عددى وضعيت سلامت عمومى در يرستاران بخش مراقبت ويزه بر حسب فرم جمعيت شناختى و بررسى ارتباط آنها تُولمال

\begin{tabular}{|c|c|c|c|c|}
\hline \multicolumn{2}{|c|}{ سلامت عمومى } & \multirow[t]{2}{*}{ ت تعداد } & \multicolumn{2}{|c|}{ 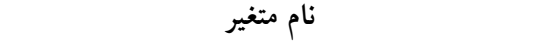 } \\
\hline نتايج آزمون & Mean \pm SD & & & \\
\hline$X^{2}=9 / v \wedge$ & $r V / T V \pm T / \varepsilon V$ & 17 & كمتر از •r & \\
\hline$d f=r$ & $r \cdot / r \pm \tau / v \varepsilon$ & $\wedge 1$ & $r \cdot-\varepsilon \cdot$ & سن (سال) \\
\hline$P=\cdot / \cdot r \mu$ & rN/9T $\pm 0 / 29$ & $r\urcorner$ & بيشتر از •ع & \\
\hline$t=-r / 0 \Lambda$ & $r V / l \cdot \pm V / r r$ & $v^{r}$ & مجرد & \\
\hline $\mathrm{df}=191$ & $r q / q \varepsilon \pm O / V \varepsilon$ & $1 \%$ & متأهل & وضعيت تأهل *** \\
\hline \multicolumn{5}{|l|}{$\mathrm{P}<\bullet / \cdot \cdot 1$} \\
\hline $\mathrm{t}=-1 / \mathrm{V} \Lambda$ & $r \Lambda / \neg \Psi \pm T / \Lambda \Gamma$ & IV. & ليسانس & \\
\hline $\mathrm{df}=191$ & $r \cdot / \tau \cdot \pm r / r \varepsilon$ & r & فوق ليسانس و بالاتر & سطح تحصيلات" \\
\hline \multicolumn{5}{|l|}{$\mathrm{P}=\cdot / \cdot \mathrm{V}\urcorner$} \\
\hline & $r 0 / 0 \cdot \pm v / 00$ & 7 & كمتر از يك و نيم & وضعيت اقتصادى (ميليون \\
\hline $\mathrm{F}=\mathrm{r} / \wedge \mathrm{T}$ & $r N / V_{0} \pm T / T^{\prime} q$ & 111 & $1 / 0-\varepsilon$ & " تومان)" \\
\hline \multirow[t]{2}{*}{$P=\cdot / \cdot r \mu$} & $r 0 / 77 \pm 7 / 9 \varepsilon$ & 7 & بيشتر از ع & \\
\hline & $r T / V \wedge \pm T / V$ & $1 \varepsilon$ & صبح & \\
\hline $\mathrm{F}=\{/ \varepsilon)$ & $r \cdot / \cdot v \pm T / r \varepsilon$ & r & شب 1 & نوبت كارى" \\
\hline \multirow[t]{2}{*}{$\mathrm{P}=\cdot / \cdot 1$} & YN/1O $\pm T / 20$ & $|\varepsilon|$ & در گردش & \\
\hline & $r q / 70 \pm 7 / 2 r$ & $1 T$. & رسمى & \\
\hline $\mathrm{F}=r / v$. & $r V / T \cdot \pm \varepsilon / T V$ & $\varepsilon$. & ق قراردادى & وضعيت استخدام" \\
\hline \multirow[t]{2}{*}{$\mathrm{P}=\cdot / \cdot 79$} & $r V / 07 \pm \wedge / 71$ & 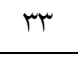 & طرحى & \\
\hline & $r N / 09 \pm V / T l$ & V. & $1-0$ & \\
\hline $\mathrm{F}=\cdot / 9 \varepsilon$ & $r \cdot / r \pm v / v o$ & or & $0-1$. & سابقه كار (سال)" \\
\hline $\mathrm{P}=\cdot / \pi \mathrm{V}$ & 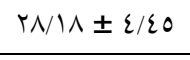 & v. & بيشتر از · & \\
\hline & $r q / T V \pm 7 / 77$ & 71 & ICU & \\
\hline & $r \Lambda / r V \pm T / 0$. & $0 \wedge$ & $\mathrm{CCU}$ & نام بخش" \\
\hline \multirow[t]{3}{*}{$\mathrm{P}=\cdot / \mathrm{V} q$} & ҮN/AT $\pm 9 / \Upsilon \wedge$ & IV & 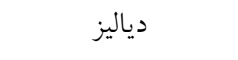 & \\
\hline & YN/QE $\pm 0 / \varepsilon q$ & ov & اورزانس & \\
\hline & TN/OV $\pm V / T Y$ & ro & $\cdot-\varepsilon \cdot$ & \\
\hline $\mathrm{F}=\cdot / 07$ & $r q / \mu \wedge \pm 0 / 10$ & v) & $\varepsilon \cdot-7$. & اضافه كار (ساعت)" \\
\hline$P=\cdot / 07$ & YN/OV \pm T/AY & $\wedge \vee$ & بيشتر از •7 & \\
\hline
\end{tabular}




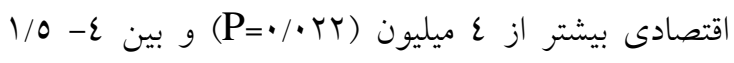

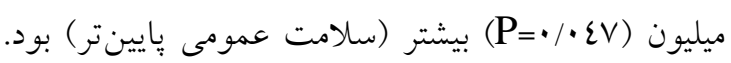
(جدول شماره ب). (جم)

در نتايج رگرسيون خطى جند گانه مشاهده مى شود وضعيت

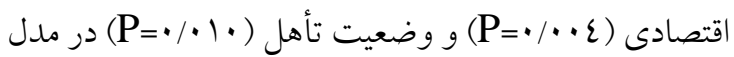
معنى دار شدند. ضريب ركرسيونى آنها به ترتيب برابر با با

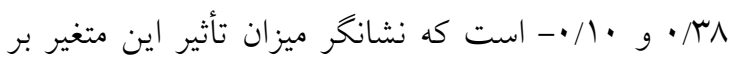
سلامت عمومى افراد است. بلدين معنى كه نمرات سلامت

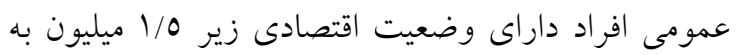
اندازه ^ץ// از افراد داراى بيشتر از ع ميليون بيشتر (سلامت عمومى پِايين تر) بود. هميجنين سلامت عمومى افراد مجرد به اندازه • 1/• واحد از افراد متأهل كمتر (سلامت عمومى بهتر) بود.( جدول شماره ع)
يافتهها نشان داد بين ميانخين سلامت عمومى با سن

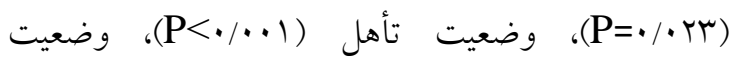
اقتصادى (سץ•/ معنى دار آمارى وجود داشت. بدين صورت كه ميانخين سلامت عمومى افراد مجرد به صورت معنىدارى از افراد

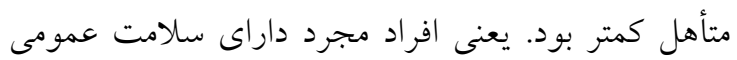
بهترى نسبت به افراد متأهل بودند. نتايج آزمون دو به دو نشان داد ميانخين سلامت عمومى افراد بين •ع-·r سال به صورت معنى دارى از افراد داراى سن كمتر از •ب سال

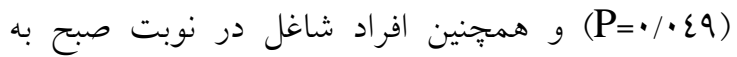
صورت معنى دارى از افراد شاغل در نوبت كارى در گردش

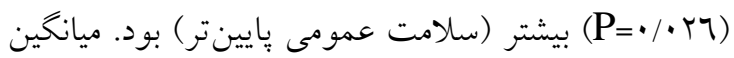
سلامت عمومى افراد داراى وضعيت اقتصادى كمتر از 1/0 ميليون نيز به صورت معنىدارى از افراد داراى وضعيت

جدول شماره ؟: رَّر سيون جند

\begin{tabular}{|c|c|c|c|c|c|c|}
\hline p-value & آماره آزمون & ضريب استاندارد & انحر اف از خطا & ضريب مدل & \multicolumn{2}{|c|}{ متغيرهاى مستقل } \\
\hline$<\cdot / \cdots 1$ & YT/qY & &.$/ 1 T$ & $r / r T$ & \multicolumn{2}{|c|}{ مقدار ثابت } \\
\hline$\cdot / \mu 1$ & $1 / \cdots 0$ &.$/ 1 r$ &.$/ \cdot 71$ & $\cdot / \cdot 71$ & كمتر از •r & \\
\hline \multirow{2}{*}{$\cdot / \pi$} & $1 / \varepsilon \wedge$ & $\cdot / \mathrm{VV}$ & .1 .01 & $\cdot / \cdot \sqrt{ } 7$ & $r \cdot-\varepsilon \cdot$ & سن \\
\hline & & مرجع & & & •ع و بالاتر & \\
\hline$\cdot / 149$ &.$/ 1 \mu$ & $.1 \cdot 10$ &.$/ .0 r$ & $\cdot / \cdots V$ & رسمى & \\
\hline \multirow[t]{2}{*}{$\cdot / \mu \Lambda$} & $-\cdot / \wedge \mathrm{V}$ & $-\cdot / \cdot \wedge$ &.$/$ or & $-\cdot / \cdot\{7$ & قراردادى & نوع قرارداد \\
\hline & & مرجع & & & طرحى & \\
\hline \multirow[t]{2}{*}{.$/ 11$} & $-1 / 09$ & $-\cdot / 11$ &.$/ \cdot 0$ & $-\cdot / \cdot 1$ & ليسانس & تحصيلات \\
\hline & & مرجع & & & فوق ليسانس و بالاتر & \\
\hline \multirow[t]{2}{*}{.$/ 1$} & $-Y / 71$ & $-\cdot / T r$ & $.1 \cdot r q$ & $-\cdot / 1$ & مجرد & \\
\hline & & مرجع & & & متأهل & وضعيت تأهل \\
\hline$\cdot / \cdot \varepsilon$ & $T / 9 T$ & $\cdot \pi$ & $\cdot / 1 \pi$ & $\cdot \pi \Lambda$ & كمتر از يك و نيم & وضعيت اقتصادى (ميليون \\
\hline \multirow[t]{2}{*}{$\cdot / T$} & $1 / 00$ & .110 & $.1 .9 \mathrm{~V}$ & $\cdot 110$ & $1 / 0-\varepsilon$ & تومان) \\
\hline & & مرجع & & & بيشتر از ع & \\
\hline.$/ 1 T$ & $1 / 0 Y$ & .1 & $\cdot 1 \cdot 71$ & .1 .94 & صبح & \\
\hline \multirow[t]{2}{*}{.$/ 17$} & $1 / \varepsilon$. & $\cdot / 1$ & $\cdot / \mu$ & $\cdot / \cdot \sum Y$ & شب & نوبت كارى \\
\hline & & مرجع & & & در گردش & \\
\hline
\end{tabular}

مطالعه kushali و همكاران در تهران با ساب يرستار، بحث و نتيجه كيرى Najafi

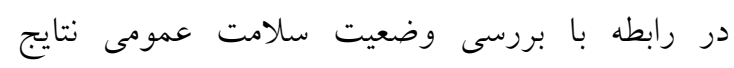

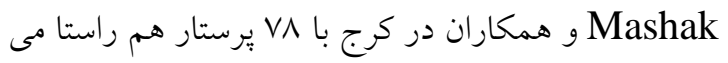

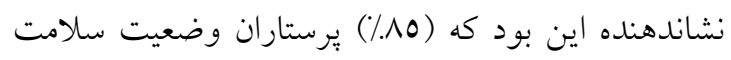

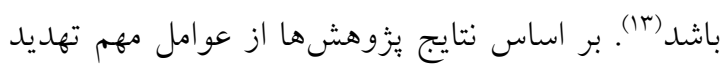
مطلوبى ندارند (جدول شماره Y) كه مطالعه حاضر با نتايج 


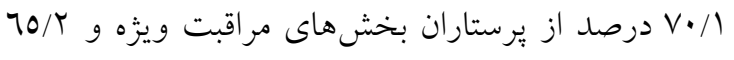
درصد از يرستاران شاغل در ساير بخشها ميزان اضطراب طبيعى داشتند هم راستا مىباشد. ولى نتايج مطالعه حاضر با نتايج مطالعه Najafi و همكاران كه نشان داد بالاترين ميانخين نمره سلامت عمومى مربوط به بعد اضطراب

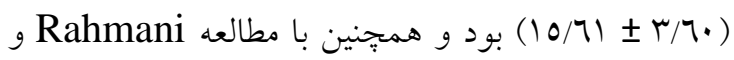

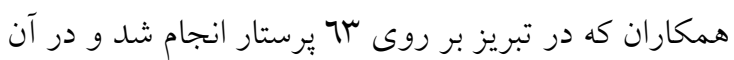

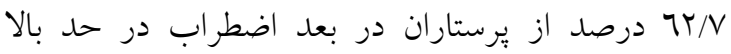
ارزيابى شدند و همجينين مطالعه Mashak و همكاران كه نشان داد (ساحرصد) از يرستاران از نظر اضطراب در سطح بالا ارزيابى شدند هم راستا نمىباشد. همجنين نتايج اين مطالعه با مطالعهاى كه در سال 11 +r در كشور يونان بر روى ساب برستار انجام شده بود و ميزان اضطراب در برستاران بخش اورزانس را در حد بالا ارزيابى كرده بود مغايرت دارد (1). همجنين نتايج مطالعه حاضر در بعد علائم افسردگى با نتايج مطالعات مقصودى، رحمانى، مهرابى و غفارى هم راستا مىباشد. هر جّند كه در مطالعه حاضر ميزان علائم اضطراب و افسردگى در برستاران شاغل در بخش مراقبت هاى ويزه بيمارستانهاى منتخب در حد يايين

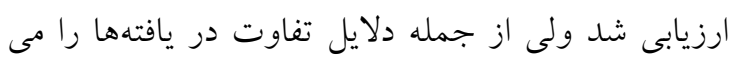
توان به تفاوت محيطهاى يزوهش، شرايط بيمارستانها، شرايط كارى برستاران در بخشها و ميزان حمايت مديران از يرستاران در ابعاد مختلف اشاره نمود. با اين حال اهميت

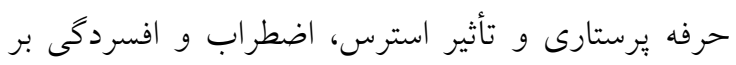
عملكرد شغلى و كيفيت خدمات دهى را نمىتوان ناديده كرفت و اين مبحث نياز به يزوهش و مطالعات بيشترى دارد، جرا كه محيط كارى بِرستاران، استرس هاى طولانى و مداوم به همراه دارد و اين موارد در افراد شاغل در حرفه هاى يارى رسان كه درگير در مشكات ديخران هستند به

$$
\text { وجود مى آيد (19). }
$$

در رابطه با بعد كاركرد اجتماعى نتايج نشانكر اين بود كه

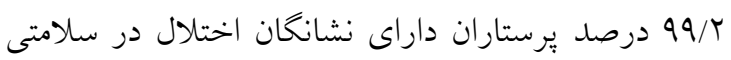
بودند. نتايج مطالعه حاضر با نتايج مطالعه مقصودى و

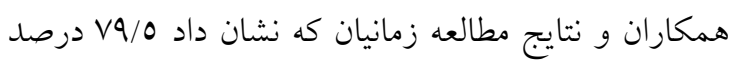

كننده سلامت روانى يرستاران مىتوان به ماهيت استرس زاى اين حرفه، فشار كارى زياد، ابهام در نقشهاى شغلى، مشكلات ارتباطى و تعارضهاى بين فردى، مشكلات هيجانى، مواجه شدن با موقعيت هاى غير قابل بيش بينى، نوبتهاى كارى متغير، عوامل سازمانى و فردى اشاره

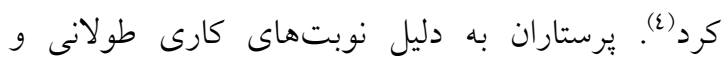

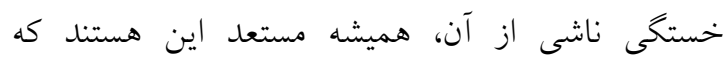
سلامتشان در ابعاد مختلف مورد تهديد قرار كيرد(عان. برستارانى كه در محيط كار تحت فشار قرار مى گيرند، سلامت جسمى روانى بيايين ترى دارند كه مىتواند كيفيت زندكى آنان را كاهش داده و مانع از توانايى آنها در ارائه لئه خدمات ايمن و مؤثر از بيمار شود(10). سازمان جهانى بهداشت (WHO) يكى روز را به عنوان روز جهانى سلامت روان تعيين كرده است تا از مردم بخواهد براى دستيابى به سلامت كامل به مسائل جسمى، روانى و اجتماعى توجه كنند (17). در رابطه با بعد علائم جسمى نتايج نشان داد كه س/7T درصد از يرستاران سلامت جسمانى مطلوبى نداشتند (جدول شماره Y). نتايج اين مطالعه با مطالعه Zamanian كه در شهر شيراز بر روى 1170 داد ع/عr درصد از يرستاران از ناراحتىهاى جسمانى

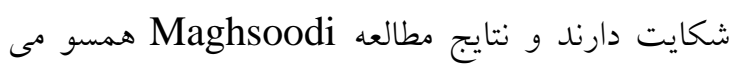
باشد (r). يرستاران به علت شرايط فيزيكى محيط كار خود دجار مشكلات جسمى متعددى مىشوند به طورى كه كمر درد شايعترين مشكل جسمى در بيش از نيمى از زنان يرستار مىباشد. در مطالعهاى كه در سال عا •r در كشور هندوستان بر روى مراقبين بهداشتى با كروه بندى (فيزيوتراب، دندانيزشك، تكنسين آزمايشخاه و پيرستار) انجام شد يرستاران بيشترين ريسك ابتلا به اختلالات عصبى - عضلانى مرتبط با كار را داشتند (IV). در رابطه با بعد علائم اضطراب و افسردگى نتايج نشانحر اين بود كه (1//0 درصد) از يرستاران در علائم اضطراب و 10/0 درصد در علائم افسردگى فاقد نشانگان اختلال در سلامتى بودند كه با نتايج مطالعه Kushali كه نشان داد 
ها، مشاورهها، كارهاى بالينى از جمله تعويض رى،

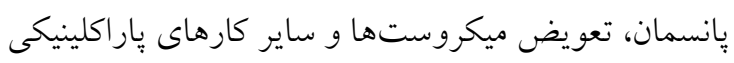

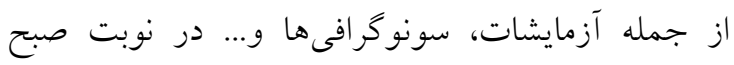
نسبت به ساير نوبتهاى كارى نسبت داد. مطالعات نشان

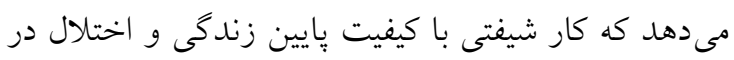

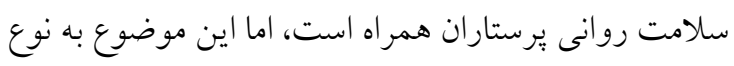

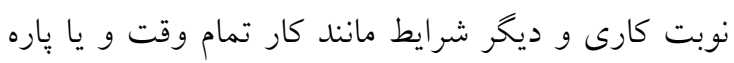

$$
\text { وقت بستخى دارد (10). }
$$

با توجه به نقش حياتى يرستاران به عنوان كادر درمان، توجه به مشكلات اين قشر و تلاش در جهت حفظ سلامت

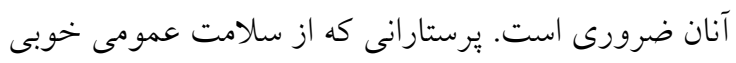

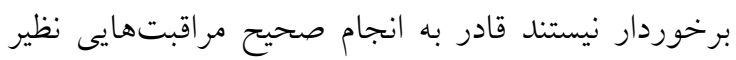

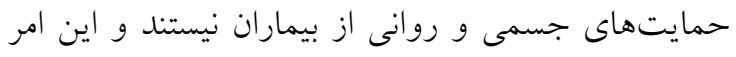

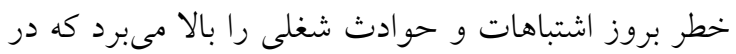
نهايت عواقب آن متوجه بيمار و برستار مىشود. در نهايت

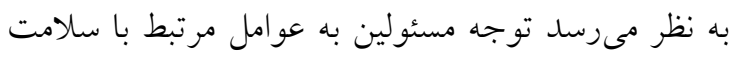

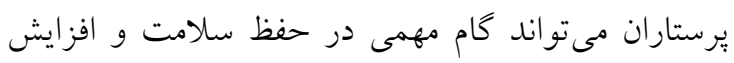
كارايى آنان داشته باشد و منجر به افزايش ماند كيفيت كار

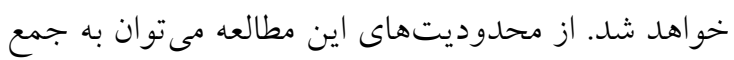

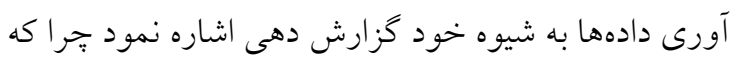
پاسخ دهى به برسشنامهها تحت تأثير عوامل محيطى مانند

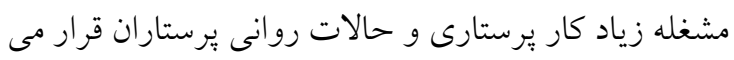

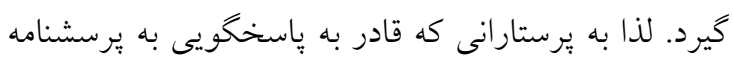

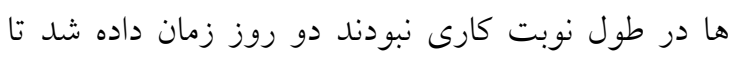
موانعى همجيون محدوديتهاى زمانى و نداشتن تمركز

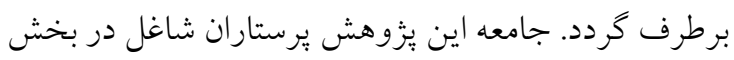

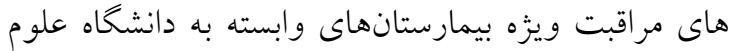
يزشكى ايران بود. با توجه به قوانين و شرايط محيطى بخش هاى مختلف و بيمارستانهاى غير دولتى بيشنهاد مىشود

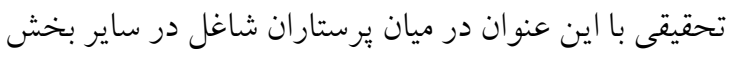

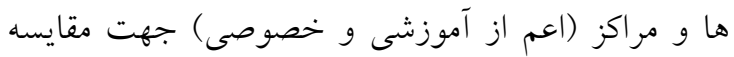

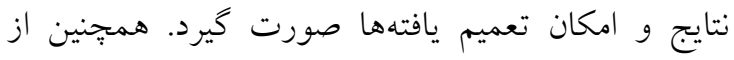
آنجايى كه بين سلامت عمومى با سن و نوبت كارى ارتباط

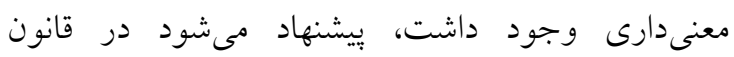

از يرستاران دجار اختلال در وضعيت كاركرد اجتماعى مى باشند هم راستا است. اختلال در عملكرد اجتماعى از جنبه

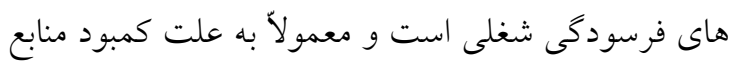
حمايتى و تعارض در كار ايجاد مىشود و در در اين ميان

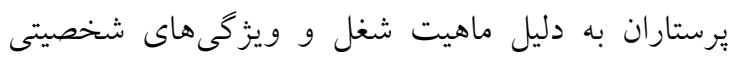
متفاوت، از نظر سلامتى بيشتر در معرض خطر هستند (r.r.r.).

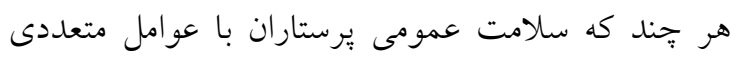

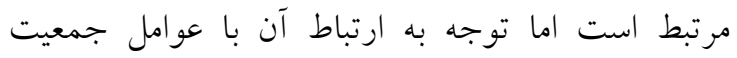

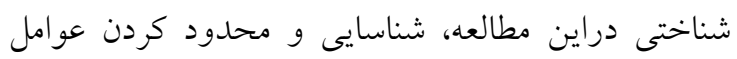

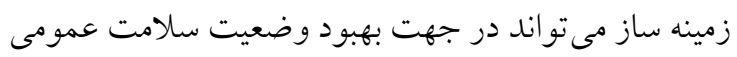

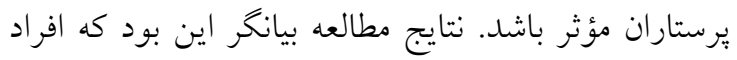

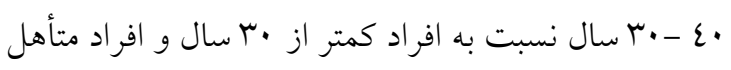

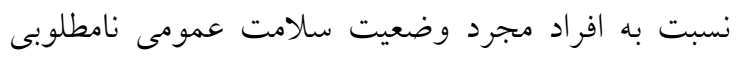
داشتند. نتايج مطالعات نشان داده است كه يرستاران متأهل

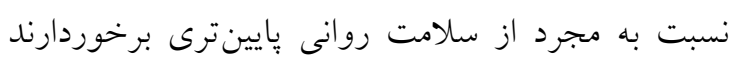

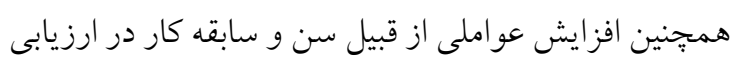

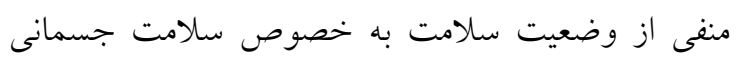

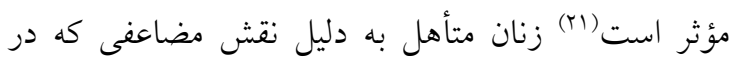

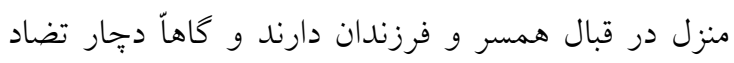

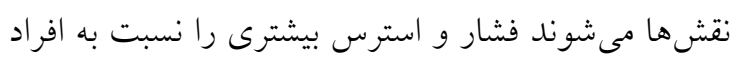
مجرد متحمل مىشوند. بيشنهاد مى شود تا جايى كه امكان

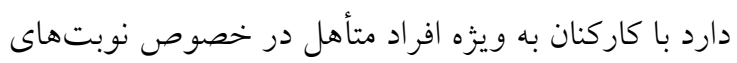
كارى درخواستى همكارى گردد.

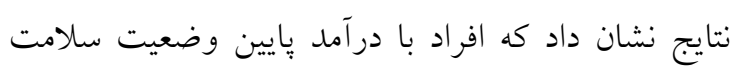
نامطلوبى نسبت به سايرين داشتند. بررسى ارتباط بين بين

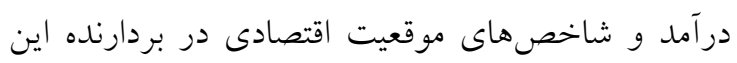

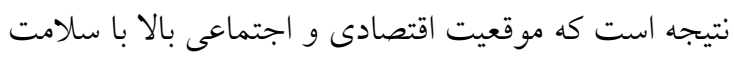

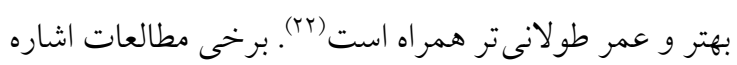

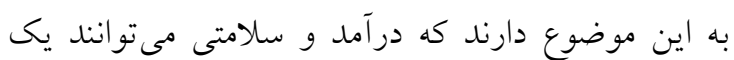

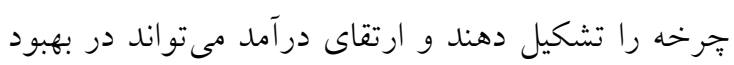
وضعيت سلامت مؤثر باشد (Tr). افراد شاغل در نوبت ثابت صبح وضعيت سلامت عمومى بلى بلاسل نامطلوبى نسبت به سايرين داشتند كه علت آن را شايد بتوان به حجم بالاى كار در نوبت صبح (از جمله ويزيت 


$$
\begin{aligned}
& \text { اين مطالعه بركرفته از پايان نامه كارشناسى ارشد رشته }
\end{aligned}
$$

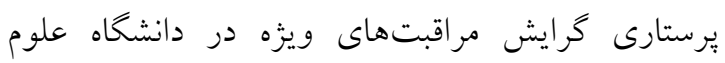

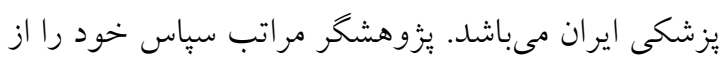

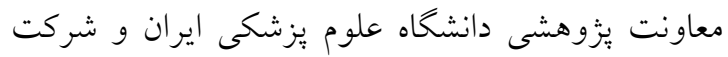

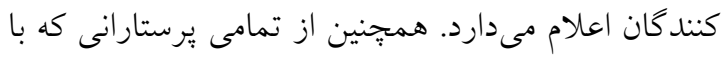

$$
\begin{aligned}
& \text { قرار دادن وقت خود جهت تكميل برسشنامه، بزوهشيكران } \\
& \text { را در انجام مطالعه يارى كردند سباسگز ارى مى شئود. }
\end{aligned}
$$

$$
\begin{aligned}
& \text { بازنشستخى و كاهش سنوات كارى يرستارن يك بازنخرى }
\end{aligned}
$$

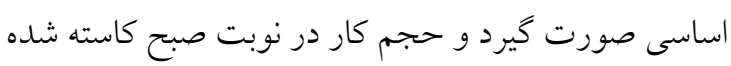

$$
\begin{aligned}
& \text { و بين ساير نوبتهاى كارى تقسيم كردد. } \\
& \text { تعارض منافع: نويسندگان هيجگگنه تعارض منافعى را } \\
& \text { كزارش نكردهاند. }
\end{aligned}
$$

تقدير و تشكر

\section{References}

1. Kamali Dehkordi F, Maghsoudi S, Emami Sigaroudi A, Kazemnejad Leili E. Study of Predictive factors of public health based on job satisfaction in employees of Rasht city Health Service Centers. Journal of Holistic Nursing And Midwifery. 2015;25(4):110-7. [Persian]

2. Maghsoodi S, Hesabi M, Monfared A. General health and related factors in employed nurses in Medical-Educational Centers in Rasht. Journal of Holistic Nursing And Midwifery. 2015;25(1):6372. [Persian]

3. Simmons BL, Nelson DL. Eustress at work: The relationship between hope and health in hospital nurses. Health Care Manag Rev. 2001;26(4):7-18.

4. Hirokawa K, Taniguchi T, Tsuchiya M, Kawakami N. Effects of a stress management program for hospital staffs on their coping strategies and interpersonal behaviors. Industrial health. 2012:MS1358.

5. Nouroozi Kushali A, Hajiamini Z, Ebadi A, Khamseh F, Rafieyan Z, Sadeghi A. Comparison of intensive care unit and general wards nurses' emotional reactions and health status. Advances in Nursing \& Midwifery. 2013;23(80):15-23. [Persian]

6. Chiou ST, Chiang JH, Huang N, Wu CH, Chien LY. Health issues among nurses in Taiwanese hospitals: National survey. Int J Nurs Stud. 2013;50(10):1377-84.

7. Qalawa SA, Hassan HE. Implications of nurse's moral distress experience in clinical practice and their health status in obstetrics and critical care settings. Clin Pract. 2017;6(2):15-25.

8. Heydariyeh I. Depression, stress and anxiety of nurses in COVID-19 pandemic in Nohe-Dey Hospital in Torbat-e-Heydariyeh city, Iran. Journal of Military Medicine. 2020;22(6):526-33. [Persian]

9. Darvishpoor Kakhki A, Ebrahim H, Alavi Majd H. Health status of nurses of hospitals dependent to Shahroud Medical University. Iran journal of Nursing. 2009 t;22(60):19-27. [Persian]

10. Goldberg DP, Hillier VF. A scaled version of the General Health Questionnaire. Psychological medicine. 1979;9(1):139-45.

11. Ebrahimi H, Kazemi A, Asghari Jafarabadi M, Azarm A. Moral distress in nurses working in educational hospitals of Northwest Medical Universities of Iran. Iranian Journal of Medical Ethics and History of Medicine. 2013;6(4):80-8. [Persian]

12. Taghavi S. Validity and reliability of the general health questionnaire (GHQ-28) in college students of Shiraz University. J Psychol. 2002;5(4):381-98.

13. Mashak B, Farhand B, Moghadam S, Pazhoom Z, Hajalikhani T, Taghipoor N, Soltannezhad N, Shahnavaz N, Farid M. Relationship Between Job Stress Among Nurses with Their General Health Status in Kamali Hospital in 1392. Alborz University Medical Journal. 2015;4(4):231-6. [Persian]

14. Keshavarz AM, Minakhani AM, Amini K, Imani A, Hamidi L, Mohammadi P, Daviran L, Pourrahimi A. The Level of Mental Health and Relationship Factors in Nurses Working in zanjan University of Medical Science Hospitals in 1395. Zanko Journal Of Medical Sciences. 2018; 19(60): 22-30. [Persian]

15. Sauer PA, McCoy TP. Nurse bullying: Impact on nurses' health. West J Nurs Res. 2017;39(12):1533-46. 
16. Hsiao SJ, Tseng HT. The impact of the moderating effect of psychological health status on nurse healthcare management information system usage intention. InHealthcare 2020;8,(1):28. Multidisciplinary Digital Publishing Institute.

17. Yasobant S, Rajkumar P. Work-related musculoskeletal disorders among health care professionals: A cross-sectional assessment of risk factors in a tertiary hospital, India. Ind J Occup Environ Med. 2014;18(2):75.

18. Stathopoulou H, Karanikola MN, Panagiotopoulou F, Papathanassoglou ED. Anxiety levels and related symptoms in emergency nursing personnel in Greece. J Emerg Nurs. 2011;37(4):314-20.

19. Taleghani E, Noroozi M, Hadavi M. Prevalence of Stress, Anxiety and Depression among Nursing Staff in Intensive Care Units of Ali Ebn-e Abitaleb Hospital in Rafsanjan in 2017. Community Health Journal. 2018;12(2):11-21. [Persian]

20. Mehrabi T, Ghazavi Z. Health assessment of female nurses of Isfahan University of Medical Sciences. J Hygiene Health. 2005;1:1-5.

21. Kilfedder CJ, Power KG, Wells TJ. Burnout in psychiatric nursing. J Adv Nur. 2001;34(3):38396.

22. Bazazian S, Rajaei YE. The Relationship between Socioeconomic Status with Mental and Physical Health. Developmental Psychology (Journal of Iranian Psychologists). 2007;3(11):237-48. [Persian]

23. Yang C. The influence of income and working time of rural migrant workers on health: The mediating effect of life stress and the moderating effect of marital status. Human Syst Manag. 2020;39(1):69-80. 